\title{
Análisis del léxico en diferentes registros textuales en la construcción del imaginario social del narcotráfico en México*
}

\author{
Rafael Saldívar Arreola* \\ Ignacio Rodríguez Sánchez ${ }^{* * *}$
}

\begin{abstract}
Resumen
El narcotráfico en México ha transformado el habla cotidiana. El propósito de este trabajo es reflexionar acerca de cómo se construye el imaginario social de lo narco a través del léxico, desde distintos ámbitos: el discurso oficial, la prensa, la investigación sociológica, la literatura, los narcocorridos, los blogs y las narcomantas. Esta investigación, de tipo cuantitativo, se basa en un corpus especializado y herramientas estadísticas como el análisis de palabras clave, frecuencias y dispersión de los términos. Con este análisis, se presenta una visión más compleja del fenómeno del narco en México, que va más allá de la visión criminalizadora que se presenta en el discurso oficial.
\end{abstract}

Palabras clave: léxico del narco, pensamiento complejo, corpus, análisis cuantitativo.

\section{Lexical analysis of different textual registers in the construction of the social imaginary of drug trafficking in Mexico}

\begin{abstract}
Drug trafficking in Mexico has transformed everyday speech. The purpose of this work is to reflect on the way in which the social imaginary of narco is constructed through the lexicon, from different fields: official discourse, the press, sociological research, literature, narcocorridos, blogs and narcomantas. This quantitative research is based on a specialized corpus, using basic statistical tools such as the analysis of keywords, frequencies and dispersion of terms. This analysis presents a more complex view of the narco phenomenon in Mexico, which goes beyond the criminalizing view that is presented in the official discourse.
\end{abstract}

Keywords: Narcolanguage, complexity, corpus, quantitative analisys.

Este artículo está asociado al proyecto "Estudio variacional del léxico del narco en la frontera", registrado ante el Departamento de Posgrado e Investigación de la UABC.

Mexicano. Doctor en Lingüística. Universidad Autónoma de Baja California, México. rafaelsaldivar@ uabc.edu.mx.

**** Español. Doctor en Lingüística. Universidad Autónoma de Querétaro, México. i.rodriguez@uaq. edu.mx. 


\section{El "narcolenguaje" en México. Breve recuento histórico}

El fenómeno del narcotráfico en México está próximo a cumplir cien años. De acuerdo a diversos estudios, fueron personas de nacionalidad china quienes introdujeron el cultivo de la adormidera en el noroeste del país, para la obtención del opio. Esto ocurría principalmente en la zona montañosa de Sinaloa. Inicialmente, el consumo del opio se limitaba a los miembros de la comunidad china. Sin embargo, en los años veinte, se desató una persecución contra los chinos, los cuales tuvieron que dejar sus tierras y cultivos en manos de los campesinos locales.

Se dice que para los años cuarenta, el cultivo de amapola se había consolidado y que incluso se estableció un convenio entre el gobierno de Estado Unidos y México para proveer del producto mexicano a los soldados que combatían en la Segunda Guerra Mundial. No obstante, de acuerdo a Enciso (2014), tal acuerdo es en realidad un mito.

En los años cincuenta, la producción de goma de opio en Sinaloa había crecido tanto que ser sinaloense era sinónimo de ser "gomero" y se calificaba a Culiacán como una ciudad en la que el narcotráfico era la actividad económica más importante (Burgos Dávila, 2013). También por esa época se comenzó a construir el imaginario social del narcotraficante, asociada al estereotipo rural del sinaloense.

En los años setenta, la lucha contra el narcotráfico se intensificó a raíz de la llamada "guerra contra las drogas" decretada por el presidente Richard Nixon. A pesar de ello, la subcultura del narcotráfico se extendió desde Sinaloa hacia el resto del país. Esta subcultura legitimaba las acciones de los traficantes y deslegitimaba las acciones de las instituciones gubernamentales. Fue entonces que el gobierno mexicano emprendió medidas de censura en contra de los llamados narcocorridos, ya que se asumía que a través de ellos fue que se expandió esta subcultura (Burgos Dávila, 2013); "quedan prohibidas todas las transmisiones que causen la corrupción del lenguaje y las contrarias a las buenas costumbres" (Astorga, 2005, p. 155).

A finales de los años setenta y principios de los ochenta, los carteles de las drogas se habían consolidado como grupos muy poderosos capaces de controlar grandes zonas del país para el traslado y la producción de drogas. Entonces, se comenzaron a hacer conocidos nombres de narcotraficantes famosos como Ernesto “Don Neto” Fonseca, Miguel Ángel Félix Gallardo y 
Rafael Caro Quintero. Conjuntamente con este fenómeno, la narcocultura se había extendido a todas las clases sociales (Burgos Dávila, 2013), principalmente a través de manifestaciones culturales como los narcocorridos (Los Tigres del Norte, Adán “Chalino” Sánchez, etc.) y las películas sobre narcotraficantes, que protagonizaban los hermanos Almada, entre otros.

Con el arresto de los narcotraficantes que tenían el control de los grupos más poderosos, durante los años noventa se inició una reestructuración al interior de los carteles, lo que marcó el surgimiento de nuevos capos, como los hermanos Arellano Félix, o Joaquín “el Chapo” Guzmán. Además, la operación de estos nuevos grupos se dio con un nivel de violencia cada vez más alto, el cual llegó a su clímax con la llegada al poder del presidente Felipe Calderón, en 2006, quien retomó el discurso de Nixon de la guerra contra las drogas y despertó en el país una ola de violencia que abarcó prácticamente todo el territorio nacional, y la cual hasta la fecha sigue vigente, dejado una enorme cantidad de muertos. De acuerdo a un reportaje de Juan Luis García Hernández (2016), al cumplirse diez años del inicio de la guerra contra el narco se han contabilizado 186,000 decesos.

De esta forma, el narcotráfico pasó de ser un fenómeno enquistado en la zona de la sierra de Sinaloa a una realidad que, en muchos sentidos, determina la vida cotidiana en todo el país. Como es de suponer, un fenómeno sociocultural de tal importancia, ha dejado su huella en el habla del mexicano. Recientemente se han desarrollado varios trabajos lexicográficos que recogen algunas voces del narcotráfico (Company, 2010; Fitch, 2011, DEM, 2017). No obstante, al ser un fenómeno complejo que involucra a diversos actores sociales y diversas esferas de interés social, es necesario también analizar su lenguaje desde la complejidad. Este es el objetivo del presente trabajo.

De acuerdo a la definición que propone Edgar Morin (1999), hay complejidad cuando son inseparables los elementos diferentes que constituyen un todo y que existe un tejido interdependiente, interactivo e interretroactivo entre el objeto de conocimiento y su contexto, las partes y el todo, el todo y las partes, las partes entre ellas. Por esto, la complejidad es la unión entre la unidad y la multiplicidad (p. 17). Consideramos que el fenómeno narco y, en especial el lenguaje utilizado para dar cuenta de él, es un ente que debe analizarse desde esta postura, ya que es imposible disociar los procesos morfológicos y semánticos de los procesos socioculturales que se entretejen para formar lo que llamamos narcolenguaje. De acuerdo a los supuestos del pensamiento complejo, ahora 
son los problemas los que determinan la metodología y los métodos de investigación y no al revés (Gallegos, 2016, p. 107).

\section{Diferentes "narcolenguajes"}

El concepto de "narcolenguaje”, el léxico hablado por las personas que se dedican al narcotráfico, se percibe principalmente como una variedad jergal dentro del habla coloquial de México, En el imaginario colectivo, incluso se ha vinculado el habla del narco con la variedad dialectal del estado de Sinaloa. Hablar como sinaloense se convirtió en emblema y en un elemento identitario de lo narco (Moreno Candil, Burgos Dávila, \& Valdez Bátiz, 2016).

Como se mencionó antes, fue precisamente en esa región del país en donde surgió el fenómeno del narcotráfico. Su posterior expansión al resto del país parece también haber diseminado varios elementos culturales propios de Sinaloa, entre ellos el léxico. Varios elementos de las historias locales de las drogas en Sinaloa se han vuelto lugares comunes en la manera en la que los mexicanos nos contamos la historia del narco (Enciso, 2014, p. 13).

No obstante, en la actualidad, el narcotráfico abarca diferentes elementos que lo componen como un fenómeno social; ya sea este entendido como un delito, una actividad económica, una fuente de empleo, una forma de vida, o como una amenaza que desestabiliza la seguridad nacional (Burgos Dávila, 2013). Esto implica que el narcotráfico no solamente involucra a traficantes de drogas, sino que es un fenómeno que implica a la sociedad en su conjunto. De acuerdo a Moreno, Burgos y Valdez (2016), en México no existe un "narcotráfico", existen más bien varios "narcotráficos" con diferentes peculiaridades y factores que se hacen presentes a escala local y global.

Así pues, el narcotráfico se experimenta de forma distinta en distintas esferas sociales, y por lo tanto también se habla de forma distinta acerca del narco. El análisis que se presenta a continuación se centra en el léxico del narco desde tres perspectivas generales que configuran el llamado "narcolenguaje": 1) el discurso oficial (discursos oficiales, notas de prensa, etc.); 2) la sociedad civil (prensa y literatura); y 3) desde el interior del propio narcotráfico ("narcocorridos", blogs y "narcomantas"). Estas tres perspectivas corresponden también a la configuración de un corpus lingüístico que se compiló con la intención de analizar empíricamente el fenómeno desde un punto de vista lingüístico. 


\section{Metodología}

El análisis de las muestras mencionadas es de tipo cuantitativo. Se basa principalmente en la comparación de palabras claves encontradas en cada uno de los subcorpus, así como las frecuencias generales. El concepto de "palabra clave", en lingüística de corpus, se refiere a una comparación de las frecuencias esperadas contra las frecuencias obtenidas en un corpus de referencia (Bondi, 2010). Es decir, cada lengua tiene palabras que regularmente son más frecuentes que otras, por lo tanto, cuando en un corpus se encuentra una palabra con una frecuencia mucho mayor o mucho menor a lo esperado en un corpus de referencia, es decir, un corpus compuesto por muestras de habla "común", se le señala como "palabra clave".

En este trabajo el corpus de referencia que se utilizó fue el CREA (Corpus de Referencia del Español Actual) el cual está disponible en la página de la RAE (Real Academia de la Lengua Española). La versión utilizada es una versión lematizada, es decir que las palabras perteneciente a una misma familia léxica se asocian a un solo termino, así como las conjugaciones de los verbos se asocian a la forma en infinitivo de este. Además, dado que los distintos subcorpus no tienen el mismo tamaño, las frecuencias que se muestran están normalizadas, es decir, se muestran ocurrencias cada 10,000 palabras.

A continuación se detallan los diferentes subcorpus que se utilizaron en el análisis, en la tabla 1:

Tabla 1. Conformación de corpus.

\begin{tabular}{|c|c|c|c|}
\hline Ámbito & Fuentes & Tokens/ Tipos & Fechas \\
\hline \multirow[t]{2}{*}{$\begin{array}{l}\text { Discurso } \\
\text { oficial }\end{array}$} & $\begin{array}{l}\text { Discursos/ Notas de } \\
\text { prensa Felipe Calderón }\end{array}$ & $153,957 / 11,209$ & 2006-2012 \\
\hline & $\begin{array}{l}\text { Discursos/ Notas de } \\
\text { prensa Enrique Peña } \\
\text { Nieto }\end{array}$ & $248,879 / 12,025$ & $2012-2016$ \\
\hline \multirow{2}{*}{$\begin{array}{l}\text { Sociedad } \\
\text { civil }\end{array}$} & Prensa & $2,059,776 / 52,760$ & 2009-2017 \\
\hline & Literatura/Ensayo & $906,278 / 59,042$ & 1994-2011 \\
\hline \multirow[t]{3}{*}{ Narcotráfico } & Narcocorridos & $81,116 / 10,411$ & 2010 \\
\hline & Blogs & $203,444 / 20,957$ & 2009-2011 \\
\hline & Narcomantas & $5,080 / 1,652$ & 2011-2013 \\
\hline Total & & $3,658,530 / 168,056$ & \\
\hline
\end{tabular}




\section{El narco desde el discurso oficial}

"La realidad social depende del lenguaje, ya que existe una relación lógica entre los actos de habla, el mundo intersubjetivo de los hechos sociales, y la estructura de las instituciones sociales" (Stubbs, 2010, p. 22). Por muchos años, el imaginario social acerca del tráfico de drogas y los traficantes era generado por la información proveniente del Estado; quien encontró un espacio propicio en una sociedad muy conservadora, y mayormente desinformada. Tanto el tráfico de drogas como los propios traficantes eran conceptualizados de acuerdo al discurso oficial, reproducido por los medios (Astorga, 2005, p. 160). Esta dinámica se acentuó aún en gran medida durante la administración del presidente Calderón (2006-2012), quien tomó la llamada "guerra contra las drogas" como su estandarte, estableciéndolo como su prioridad en las decisiones políticas.

Las razones para iniciar esta guerra contra el narco no han quedado del todo claras. Hay quien supone que en el fondo había una intención de legitimar al nuevo gobierno después de haber ganado en un proceso electoral dudoso, y quienes entienden que esta decisión simplemente obedeció a la propia formación del presidente, quien se había caracterizado por ser extremadamente conservador y muy apegado a las políticas proestadounidenses. Sean cuales fueren las razones, se recurrió a una estrategia discursiva que buscaba hacer parecer al fenómeno del narcotráfico como el principal riesgo para la estabilidad social. De tal forma, se apeló a un discurso oficial respecto al narcotráfico creado por la retórica estadounidense acerca de la guerra contra las drogas (Dueñas, 2013). Así, los medios de comunicación reforzaron una forma de representación criminalizada y psicopatologizante del fenómeno del narcotráfico y de las personas inmiscuidas (Luján Christiansen, 2016).

De esta forma, el lenguaje se vio invadido, más que en cualquier otro periodo, por los códigos de guerra que buscaban conformar una cultura de miedo; a través de la percepción de inseguridad y la interiorización de la violencia (Rodríguez Rejas, 2014, p. 132). La llamada "narcoviolencia” remite a un conjunto de prácticas enlazadas que se clasifican de esa forma en función de cómo hemos definido ese tipo particular de violencia(Luján Christiansen, 2016, p. 31).

En la investigación que se reporta aquí, se hizo un análisis de las palabras clave de las notas de prensa referentes al tema de seguridad pública, publicadas en el portal de la Presidencia de la República durante el pri- 
mer año del mandato de Felipe Calderón; es decir, desde el primero de diciembre de 2006 hasta el primero de diciembre de 2007.

Al analizar las palabras clave se encontró que la preposición "contra" tiene un keyness muy elevado; incluso se ubica en el lugar 37 de las palabras más frecuentes de los discursos de Calderón en ese periodo. Esta palabra se utiliza en frasemas como "la guerra contra el narcotráfico". Así mismo, se encuentran variaciones de esta palabra como "lucha" o "batalla" contra la delincuencia, el crimen organizado, la inseguridad o el narco. La palabra "guerra" aparece en 34 ocasiones y el frasema más común es "ganar la guerra/ perder la guerra"; lo que confirma lo mencionado anteriormente respecto al discurso adoptado de ideología republicana estadounidense.

Para poder hacer una comparación entre los dos presidentes, se normalizaron las frecuencias absolutas, ya que el corpus de discursos de Peña Nieto es de casi dos veces el tamaño del de Calderón. Se normalizaron a ocurrencias cada 10,000 palabras. En la tabla 2 se ven la comparación.

Tabla 2. Algunas palabras clave de los discursos del Presidente Felipe Calderón.

\begin{tabular}{|l|c|c|c|}
\hline Término & $\begin{array}{c}\text { Frecuencia } \\
\text { (Tokens) }\end{array}$ & $\begin{array}{c}\text { Frecuencia } \\
\text { Normalizada } \\
(\mathbf{1 0 , 0 0 0})\end{array}$ & Keyness \\
\hline 1. Contra & 357 & 23.19 & 1234.59 \\
\hline 2. Delincuencia & 341 & 22.15 & 1188.88 \\
\hline 3. Crimen & 277 & 17.99 & 963.67 \\
\hline 4. Lucha & 164 & 10.65 & 557.27 \\
\hline 5. Combate & 145 & 9.42 & 499.60 \\
\hline 6. Defensa & 144 & 9.35 & 496.09 \\
\hline 7. Operativo & 113 & 7.34 & 378.95 \\
\hline 8. Narcotráfico & 110 & 7.14 & 376.76 \\
\hline 9. Estrategia & 112 & 7.27 & 375.46 \\
\hline 10. Violencia & 109 & 7.08 & 373.25 \\
\hline
\end{tabular}

Como se puede ver en las tablas, el discurso del actual presidente de México, Enrique Peña Nieto, no ha variado mucho al del Presidente Calderón respecto al fenómeno del narcotráfico. Se mantiene el tema de la guerra contra las drogas en la que se percibe al narcotráfico como un enemigo ajeno a la propia sociedad. Lo que sí se puede percibir al comparar las frecuencias normalizadas es que en el discurso del presidente 
Calderón las referencias al tema del narcotráfico son mayores a las utilizadas en el discurso de Peña Nieto; tal como se ve en la tabla 3.

Tabla 3. Algunas palabras clave de los discursos del Presidente Enrique Peña.

\begin{tabular}{|l|c|c|c|}
\hline Término & $\begin{array}{c}\text { Frecuencia } \\
\text { (Tokens) }\end{array}$ & $\begin{array}{c}\text { Frecuencia } \\
\text { Normalizada } \\
(\mathbf{1 0 , 0 0 0 )}\end{array}$ & Keyness \\
\hline 1. Violencia & 471 & 18.92 & 1082.37 \\
\hline 2. Contra & 470 & 18.88 & 1069.25 \\
\hline 3. Delitos & 407 & 16.35 & 933.74 \\
\hline 4. Víctimas & 336 & 13.50 & 768.92 \\
\hline 5. Operaciones & 282 & 11.33 & 643.62 \\
\hline 6. Delincuencia & 271 & 10.89 & 618.10 \\
\hline 7. Armas & 190 & 7.63 & 421.35 \\
\hline 8. Drogas & 158 & 6.35 & 356.25 \\
\hline 9. Fuerza & 158 & 6.35 & 356.25 \\
\hline 10. Combate & 157 & 6.31 & 353.94 \\
\hline
\end{tabular}

El principal dispositivo en la formación de opinión masiva son los espacios mediáticos (Luján Christiansen, 2016, p. 32). Así pues, el discurso de la guerra sigue siendo utilizado para legitimar las acciones que se emprenden en contra del narcotráfico. Desde esta perspectiva, la guerra contra el narcotráfico también es una guerra cultural, en la que se busca satanizar cualquier manifestación asociada al narcotráfico (Burgos Dávila, 2013, p. 176).

\section{El léxico del narco en la prensa}

En los últimos años, la prensa en México ha tenido en el fenómeno del narcotráfico un tema recurrente. Siguiendo también el matiz del discurso oficial, el énfasis que se ha dado al tema del narcotráfico también ha sido el de la violencia generada por la operación de los diferentes grupos delictivos o bien por lasacciones de las autoridades por detener estas operaciones.

Para analizar el léxico del narco utilizado en la prensa, se elaboró un subcorpus de periódicos diversos (2,059,776 tokens) y se identificaron las palabras clave referentes al narco. En la tabla 4, a continuación, se muestran los términos con el índice más alto. 
Tabla 4. Términos vinculados a la actividad delictiva.

\begin{tabular}{|l|l|l|l|l|l|}
\hline Término & \multicolumn{1}{|c|}{$\begin{array}{c}\text { FR } \\
(\mathbf{c} / \mathbf{1 0 , 0 0 0})\end{array}$} & \multicolumn{1}{|c|}{ Keyness } & \multicolumn{1}{|c|}{ Término } & $\begin{array}{c}\text { FR } \\
(\mathbf{c} / \mathbf{1 0 , 0 0 0})\end{array}$ & \multicolumn{1}{|c|}{ Keyness } \\
\hline Policía & 9.9 & 6547.27 & Muerte & 2.0 & 1336.827 \\
\hline Seguridad & 7.0 & 4637.51 & Operativo & 1.6 & 1050.364 \\
\hline Agentes & 5.1 & 3386.63 & Delincuencia & 1.3 & 888.035 \\
\hline Autoridades & 4.6 & 3068.33 & Ministeriales & 1.2 & 798.914 \\
\hline Justicia & 3.7 & 2460.39 & Delincuentes & 1.1 & 779.816 \\
\hline Elementos & 3.1 & 2043.43 & Detenciones & 1.0 & 719.34 \\
\hline Violencia & 2.9 & 1932.03 & Criminales & 1.0 & 716.158 \\
\hline Federales & 2.5 & 1702.86 & Calibre & 1.0 & 658.865 \\
\hline Crimen & 2.4 & 1636.02 & Inseguridad & 0.9 & 627.036 \\
\hline Detenidos & 2.3 & 1530.98 & Coca & 0.9 & 627.036 \\
\hline Droga & 2.3 & 1530.98 & Sicarios & 0.8 & 576.109 \\
\hline Narcotráfico & 2.2 & 1492.79 & Narco & 0.8 & 553.829 \\
\hline
\end{tabular}

Como se observa, el tema principal de la prensa escrita son las acciones de las autoridades en el combate al narcotráfico. Otro tema que destaca es la violencia; los medios a través de las cuales se efectúa y las consecuencias de esta.

La palabra "narcotraficante" surge a finales de los años cincuenta en la prensa de la Ciudad de México" (Astorga, 2005, p. 146). Así pues, la prensa ha tenido un papel muy importante en la creación del imaginario social de lo narco. El discurso de la guerra contra las drogas creo el mito del narcotraficante (Astorga, 2004).

Incluso existen términos referentes al narco que solamente se encuentran en el subcorpus de prensa y no en los otros registros analizados aquí. Por ejemplo, palabras como narcolaboratorio, narcopista o narcotúnel, únicamente son utilizados por la prensa. De acuerdo con Astorga: "el prefijo narco será empleado posteriormente como multiplicador de etiquetas estigmáticas. Importará más la pirotecnia retórica que la precisión conceptual" (Astorga, 2005, p. 146). Corroborando esta aseveración, en el corpus se encontraron 62 términos que utilizan el prefijo narco, como se puede ver en la tabla 5 . 
Tabla 5. Términos con el prefijo "narco" usados en la prensa.

\begin{tabular}{|l|l|l|l|}
\hline Narco & Narcodólares & Narcolancheros & Narcopolítico \\
\hline Narco jet & Narcoeconomía & Narcolandia & Narcopoquitero \\
\hline Narcoabogado & Narcoempresario & Narcolenguaje & Narcoposada \\
\hline Narcoabuelita & Narcoestado & Narcómano & Narcoprocurador \\
\hline Narcobajador & Narcofiesta & Narcomensaje & Narcorival \\
\hline Narcobatalla & Narcofosa & Narcomenudista & Narcosacrílego \\
\hline Narcobloqueo & Narcoguerra & Narcomoda & Narcosatánicas \\
\hline Narcocampamento & Narcogobierno & Narcomundo & Narcosoldado \\
\hline Narcocantante & Narcogrupero & Narcomunicipio & Narcoterrorismo \\
\hline Narcocasa & Narcogrupo & Narcomúsica & Narcotumba \\
\hline Narcocorridos & Narcoguerrilla & Narconegocio & Narcotúnel \\
\hline Narcocripta & Narcojardín & Narcopanista & Narcovideo \\
\hline Narcocumbre & Narcoinsurgencia & Narcopedófilo & Narquillo \\
\hline Narcocultura & Narcojudicial & Narcopintas & Narquitecto \\
\hline Narcodecomiso & Narcojuniors & Narcopolicía & \\
\hline Narcodependencia & Narcolaboratorio & Narcopolítica & \\
\hline
\end{tabular}

\section{El narco en la literatura}

En los últimos años se han publicado una gran cantidad de libros cuyo tema central es el narcotráfico. Estos se podrían dividir en dos géneros principalmente: el ensayo periodístico y la novela. Ambos géneros han colaborado en la construcción del imaginario de lo narco en México.

En el género del ensayo periodístico, sobresalen autores como Héctor de Mauleón, Javier Valdez, Ricardo Ravelo, Anabel Hernández, Víctor Ronquillo, entre otros. Estos autores tienen en común la profesión del periodismo. En general, se sigue una narrativa similar a los de la prensa, y, de acuerdo a la propuesta de Greimas (1987), se centran en los actantes: las autoridades, y los narcotraficantes. Ver tabla 6.

Tabla 6. Palabras clave en ensayos y obras literarias.

\begin{tabular}{|l|l|l|l|l|l|}
\hline Término & $\begin{array}{l}\text { FR } \\
(\mathbf{c} / \mathbf{1 0 , 0 0 0})\end{array}$ & Keyness & Término & $\begin{array}{l}\text { FR } \\
(\mathbf{c} / \mathbf{1 0 , 0 0 0})\end{array}$ & Keyness \\
\hline Narcotráfico & 8.2 & 4523.19 & Muerte & 3.6 & 2013.65 \\
\hline Chapo & 7.7 & 4218.89 & Narcotraficante & 3.4 & 1863.37 \\
\hline Narco & 6.7 & 3670.40 & Cocaína & 3.2 & 1788.24 \\
\hline Cártel & 6.6 & 3610.29 & Comandante & 3.2 & 1769.45 \\
\hline Carrillo & 6.5 & 3568.97 & DEA & 2.9 & 1585.37 \\
\hline Policía & 5.9 & 3223.34 & Agentes & 2.8 & 1536.53 \\
\hline Seguridad & 5.6 & 3095.6 & Ejército & 2.6 & 1461.39 \\
\hline Drogas & 5.4 & 2990.42 & Violencia & 2.6 & 1446.37 \\
\hline Penal & 4.1 & 2239.05 & Autoridades & 2.6 & 1431.34 \\
\hline Capo & 3.8 & 2103.81 & Narcos & 2.3 & 1288.58 \\
\hline
\end{tabular}


No obstante, estas publicaciones profundizan más en el tema y muestran algunas aristas que no se observan en los periódicos, por ejemplo, el aspecto humano de las personas que se involucran o se ven involucradas en la operación de los carteles. Estos textos permiten visualizar de manera más clara la complejidad del fenómeno. Se destaca que varias de las palabras de uso exclusivo describen la visión de los consumidores de drogas, con referencias a drogas, utensilios para el consumo de la droga, o aspectos relacionados con el proceso de adquisición de las drogas. A continuación, en la tabla 7 , se presentan algunos de los términos que ocurren exclusivamente en textos literarios y en ensayos.

Tabla 7. Términos de uso exclusivo en ensayos y obras literarias.

\begin{tabular}{|c|c|c|c|c|c|}
\hline Término & $\begin{array}{l}\text { FR } \\
(c / 10,000)\end{array}$ & Keyness & Término & $\begin{array}{l}\text { FR } \\
(c / 10,000)\end{array}$ & Keyness \\
\hline Cuerazos $^{1}$ & 0.28 & 157.786 & Doblado $^{2}$ & 0.05 & 30.054 \\
\hline Curarse & 0.22 & 120.178 & Speed $^{3}$ & 0.04 & 26.298 \\
\hline Rayas $^{4}$ & 0.20 & 112.704 & Talonear $^{5}$ & 0.04 & 22.541 \\
\hline Narcomundo & 0.19 & 108.947 & Traquis $^{6}$ & 0.04 & 22.541 \\
\hline Cuete $^{7}$ & 0.15 & 86.407 & Pasadores $^{8}$ & 0.03 & 18.784 \\
\hline Insulina $^{9}$ & 0.09 & 52.595 & Cacharro $^{10}$ & 0.02 & 15.027 \\
\hline Pacheco $^{11}$ & 0.09 & 52.595 & Erres $^{12}$ & 0.02 & 15.027 \\
\hline Yongos $^{13}$ & 0.08 & 45.082 & Graperos $^{14}$ & 0.02 & 11.270 \\
\hline $\begin{array}{l}\text { Engordar la } \\
\text { vena }^{15}\end{array}$ & 0.06 & 37.568 & Bacha $^{16}$ & 0.02 & 11.270 \\
\hline MDMA & 0.06 & 33.811 & Rush $^{17}$ & 0.02 & 11.270 \\
\hline
\end{tabular}

En cuanto a la novela sobre el narco, se puede afirmar que en los últimos años es uno de los géneros literarios más redituables, no solamente en México, sino en muchos países de habla hispana. Dueñas (2013) afirma

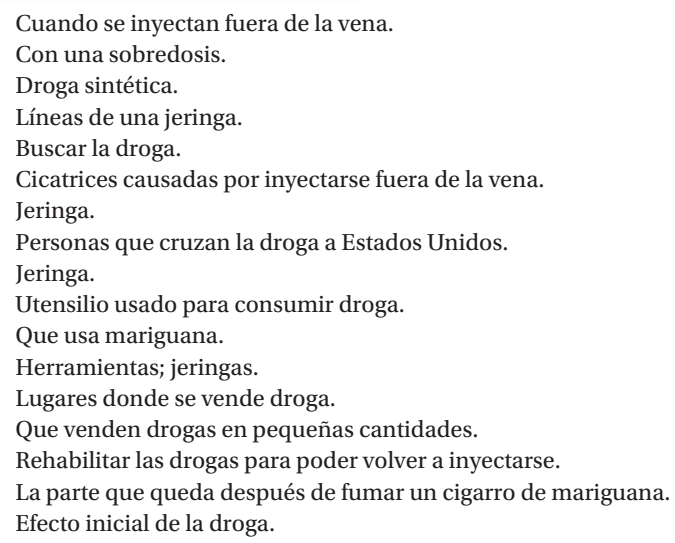


que no es tan raro que un fenómeno social o político cause el desarrollo de un género literario. En el caso del narcotráfico, ha emergido un tipo de hiperrealismo, caracterizado por un número de clichés que combinan armas, policía, sangre y todo aquello que le gusta al público.

Curiosamente, esa fachada de narcoficción amortigua su carácter amenazante al mismo tiempo que muestra aristas más amables (y atractivas) sobre el narcomundo (Luján Christiansen, 2016, p. 33). Es decir, pareciera que en lugar de causar horror en el lector, a través de este tipo de descripciones explícitas de violencia y otras actividades al margen de la ley, se generan una gran fascinación por los personajes involucrados.

\section{El léxico del narco en narcocorridos y narcomantas}

En los apartados anteriores, hemos visto cómo se habla del narcotráfico desde el exterior del fenómeno. Sin embargo, los narcotraficantes tienen sus propios medios para comunicarse. A través de los narcocorridos y de las narcomantas es posible conocer la forma en que las personas que forman parte de los carteles se comunican entre sí o como conceptualizan el propio fenómeno narco. El análisis de narcocorridos es un método alternativo para conocer del narcotráfico (Astorga, 2004).

Una de las razones por las que los narcocorridos permiten conocer mejor el fenómeno narco es que permite tener una visión más amplia de los actores sociales que participan en dicho fenómeno, alejándose del maniqueísmo que establece el discurso oficial. La mayor parte de los agentes sociales que conforman el campo del tráfico de drogas está representada en los corridos: campesinos, "burros" o "mulas", pilotos de avionetas, choferes de camiones de carga, pistoleros, "poquiteros", grandes traficantes, policías, militares, políticos (Astorga, 1997).

Por otra parte, los narcocorridos constituyen un elemento central en la representación del narcotráfico (Moreno Candil, Burgos Dávila, \& Valdez Bátiz, 2016). Es decir, las palabras utilizadas en los narcocorridos tienen un valor icónico. Esto se puede percibir en que muchos de estos términos son tomados por los escritores de narconovelas para caracterizar a sus personajes. Términos como “compa”, “plebada”, “raza”, “pariente”, “viejón” y "camarada" son expresiones de familiaridad utilizados sobre todo en el estado de Sinaloa, pero ampliamente reconocidos como usados por los narcotraficantes en todo México. En la tabla 8 se ven algunos ejemplos. 
Tabla 8. Términos de uso exclusivo en narcocorridos.

\begin{tabular}{|c|c|c|c|c|c|}
\hline Término & $\begin{array}{l}\text { FR } \\
(\mathrm{c} / \\
10,000)\end{array}$ & Keyness & Término & $\begin{array}{l}\text { FR } \\
(\mathrm{c} / \\
10,000)\end{array}$ & Keyness \\
\hline Clave $^{18}$ & 5.62 & 525.342 & Alterado $^{19}$ & 1.18 & 110.598 \\
\hline Plebada & 5.32 & 497.693 & Camaradas & 1.18 & 110.598 \\
\hline Ondeado $^{20}$ & 3.25 & 304.145 & Fajada & 1.08 & 101.382 \\
\hline Arremangar ${ }^{21}$ & 2.26 & 211.980 & Grifo $^{22}$ & 0.59 & 55.299 \\
\hline Pase $^{23}$ & 2.26 & 211.980 & Kush $^{24}$ & 0.59 & 55.299 \\
\hline Lavada $^{25}$ & 1.77 & 165.898 & Enfierrado $^{26}$ & 0.59 & 55.299 \\
\hline Primo & 1.67 & 156.681 & Enclicado $^{27}$ & 0.49 & 46.083 \\
\hline Empecherado $^{28}$ & 1.57 & 147.464 & Cocodrilo $^{29}$ & 0.49 & 46.083 \\
\hline Cargadores & 1.38 & 129.031 & Hielera $^{30}$ & 0.49 & 46.083 \\
\hline Prelavada & 1.28 & 119.815 & Arremangado $^{31}$ & 0.29 & 27.650 \\
\hline
\end{tabular}

Los escritores de novelas sobre el narco no comparten el mismo universo semiótico que los narcos. Es decir, a pesar de que estos autores viven en las ciudades en que el narcotráfico está muy presente, no pertenecen a los carteles. Sin embargo, las canciones se producen dentro del mismo mundo, por lo tanto, reflejan valores y perspectivas comunes (Dueñas, 2013, p. 10).

La relación entre el lenguaje usado por los narcotraficantes y el lenguaje usado en las canciones es simbiótica. Es decir, los compositores toman los términos de la convivencia con personas que se dedican al narco y, a su vez, los narcotraficantes toman expresiones de las canciones para incorporarlas a su léxico. De acuerdo a Horacio Contreras (2015), el narcocorrido es a petición del narco, paga la producción y para que se empiece a difundir; es un autoelogio, es una justificación de una actividad criminal. A continuación, en la tabla 9, se presentan las palabras clave del subcorpus de narcocorridos, que tiene un total de 81,216 tokens.

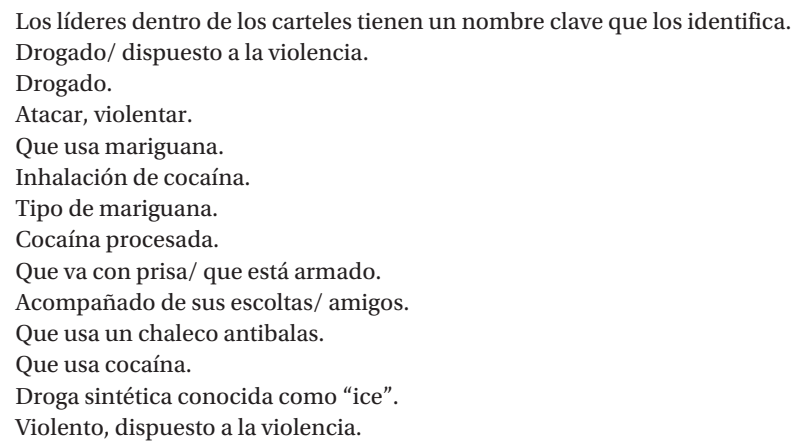


Tabla 9. Términos más frecuentes en subcorpus de narcocorridos.

\begin{tabular}{|l|l|l|l|l|l|}
\hline Término & $\begin{array}{l}\text { FR } \\
(\mathbf{c} / \mathbf{1 0 , 0 0 0})\end{array}$ & Keyness & Término & $\begin{array}{l}\text { FR } \\
(\mathbf{c} / \mathbf{1 0 , 0 0 0})\end{array}$ & Keyness \\
\hline Compa & 19.40 & 1815.656 & Poder & 5.51 & 516.126 \\
\hline Muerte & 11.62 & 1087.550 & Plebada $^{32}$ & 5.32 & 497.693 \\
\hline Jefe & 10.34 & 967.735 & Cartel & 5.22 & 488.476 \\
\hline Dinero & 8.96 & 838.704 & Trabajo & 5.02 & 470.043 \\
\hline Sangre & 7.58 & 709.673 & Fiesta & 4.92 & 460.826 \\
\hline Armas & 7.48 & 700.456 & Respeto & 4.72 & 442.393 \\
\hline Cuerno & 7.19 & 672.807 & Comandante & 4.53 & 423.960 \\
\hline Negocio & 5.81 & 543.775 & Plaza & 4.53 & 423.960 \\
\hline Mafia & 5.71 & 534.559 & Miedo & 4.43 & 414.744 \\
\hline Carros & 5.61 & 525.342 & Clave ${ }^{33}$ & 4.13 & 387.094 \\
\hline
\end{tabular}

Como se observa, las palabras clave reflejan el sistema de valores que se atribuyen a los narcotraficantes: se habla de riqueza (dinero, negocios, carros), reconocimiento (poder, respeto, jefe, clave), placer (fiesta, plebada), y la violencia como el instrumento para conseguir las anteriores (muerte, sangre, miedo, armas, cuernos de chivo).

Otro medio que no deja lugar a dudas respecto a su autenticidad como autoría de narcotraficantes son las narcomantas. Se compiló un subcorpus de 5080 tokens. Las narcomantas son mensajes que los narcos utilizan para mandar mensajes a grupos rivales o a las autoridades. Es decir, son comunicados oficiales de los diferentes carteles. Son colocados en puentes o lugares visibles, y muchas veces se dejan sobre los cuerpos de personas victimadas para reforzar el mensaje intimidatorio de las mantas. Como se observa en la tabla 10, el léxico utilizado en estas mantas tiene un carácter institucional, y es usualmente escueto. No obstante, en ocasiones se utilizan expresiones grandilocuentes que resaltan el valor y la decisión de quienes firman dichos mensajes: "somos gallos jugados que sabemos enfrentarnos a nuestro destino".

\footnotetext{
32 Es un coloquialismo para llamar a los jóvenes.

33 A los narco de alto nivel se les asigna un nombre clave; en una relación metonímica se les llama claves a los narcos de alto nivel.
} 
Tabla 10. Palabras más frecuentes en narcomantas.

\begin{tabular}{|l|l|l|l|l|l|}
\hline Término & $\begin{array}{l}\text { FR } \\
(\mathbf{c} / \mathbf{1 0}, \mathbf{0 0 0})\end{array}$ & Keyness & Término & $\begin{array}{l}\text { FR } \\
(\mathbf{c} / \mathbf{1 0 , 0 0 0})\end{array}$ & Keyness \\
\hline Cartel & 37.40 & 280.042 & Michoacana & 15.74 & 117.911 \\
\hline Gente & 33.46 & 250.561 & Poder & 15.74 & 117.911 \\
\hline Gobierno & 23.62 & 176.867 & Familia & 13.77 & 103.172 \\
\hline Sociedad & 23.62 & 176.867 & Carnal & 11.81 & 88.433 \\
\hline Templarios & 23.62 & 176.867 & Contra & 11.81 & 88.433 \\
\hline Caballeros & 21.65 & 162.128 & Hermandad & 11.81 & 88.433 \\
\hline CDG & 21.65 & 162.128 & Jefe & 11.81 & 88.433 \\
\hline Grupo & 19.68 & 147.389 & Líder & 11.81 & 88.433 \\
\hline Zetas & 19.68 & 147.389 & Madre & 11.81 & 88.433 \\
\hline Guerra & 15.74 & 117.911 & Mierda & 11.81 & 88.433 \\
\hline
\end{tabular}

Por las características antes mencionadas, estos mensajes reflejan también las distintas dinámicas de interacción de los carteles, haciendo referencias a personas en específico y a distintas agrupaciones. La tabla anterior se elaboró con textos del 2011 al 2013, sin embargo, en un estudio que aún está en proceso, ya se encuentran algunas referencias a fenómenos vigentes, como las disputas por la extracción de combustible de los ductos de PEMEX, como se puede ver en el siguiente ejemplo: "Exigimos se investigue a ..., quien es el jefe de todos los chupa-ductos de Pemex de Michoacán y Guanajuato." También se encuentran referencias a nuevos actores en el mundo del narcotráfico tales como "Los espartanos", “Cartel de Tijuana Nueva Generación”, entre otros, los cuales no existían en el año 2013. No se encontraron términos de uso exclusivo en narcomantas.

Con el incremento de la comunicación a través del internet, la información acerca del narco es mucho más accesible. En estos sitios dedicados al tema del narco muchos miembros, o simpatizantes, de los diferentes carteles publican comentarios y mensajes de toda índole; en ocasiones para comunicarse con sus asociados o bien para amenazar a sus rivales. El vocabulario manejado en este medio revela otra arista del narcolenguaje: el habla utilizada en la cotidianidad de las personas inmiscuidas en el narcotráfico. En la tabla 11, se presenta una tabla con las palabras que tienen un keyness más alto en blogs acerca del narco. 
Tabla 11. Palabras más frecuentes en blogs.

\begin{tabular}{|l|l|l|l|l|l|}
\hline Término & FR (c/10,000) & Keyness & Término & FR (c/10,0oo) & Keyness \\
\hline Narco & 15.33 & 2311.09 & CAF & 4.71 & 711.106 \\
\hline Gobierno & 12.77 & 1925.911 & Sicarios & 4.71 & 711.106 \\
\hline Policía & 11.10 & 1674.061 & Mugrosos & 4.66 & 703.698 \\
\hline Ejército & 8.25 & 1244.435 & Autoridades & 4.62 & 696.291 \\
\hline Malandros & 8.11 & 1222.213 & Chapo & 4.42 & 666.662 \\
\hline Armas & 6.19 & 933.326 & Miedo & 4.37 & 659.254 \\
\hline Cartel & 5.84 & 881.475 & Seguridad & 3.88 & 585.181 \\
\hline Muerte & 5.70 & 859.253 & Crimen & 3.53 & 533.329 \\
\hline Federales & 5.35 & 807.401 & Droga & 3.53 & 533.329 \\
\hline Poder & 4.96 & 748.142 & Corruptos & 3.48 & 525.922 \\
\hline
\end{tabular}

Como se puede ver, el tema de la muerte y la violencia sigue destacando, no obstante, también se hacen presentes las referencias a carteles y a personajes destacados dentro de los mismos. Por otra parte, también surgen términos derogatorios hacia los rivales de otros carteles o bien hacia las autoridades. En la tabla 12, se presentan algunos términos de uso exclusivo del subcorpus de blogs. En ella, se observa que el tono sigue siendo derogatorio, aunque aquí los destinatarios son principalmente los usuarios de drogas y aquellos que se ostentan como narcos sin serlo necesariamente.

Tabla 12. Términos exclusivos de blogs.

\begin{tabular}{|l|l|l|l|l|l|}
\hline Término & FR (c/10,000) & Keyness & Término & FR (c/10,0oo) & Keyness \\
\hline Manguera & 1.96 & 296.30 & Municirata & 0.09 & 14.81 \\
\hline Dedo & 1.76 & 266.66 & Policarpios & 0.09 & 14.81 \\
\hline Chinola & 1.32 & 185.16 & Narcolandia & 0.09 & 14.81 \\
\hline Crico & 0.63 & 96.28 & Drive by & 0.09 & 14.81 \\
\hline Chacuil & 0.54 & 81.47 & Policarpio & 0.09 & 14.81 \\
\hline Cristalón & 0.49 & 74.06 & Chacalear & 0.04 & 7.40 \\
\hline Manguerear & 0.14 & 22.22 & Foquero & 0.04 & 7.40 \\
\hline Aguachilero & 0.14 & 22.22 & Kilates & 0.04 & 7.40 \\
\hline Balconear & 0.14 & 22.22 & Focazo & 0.04 & 7.40 \\
\hline Killer & 0.09 & 14.81 & Malandrinear & 0.04 & 7.40 \\
\hline
\end{tabular}

\section{Conclusiones}

El narcotráfico en México es probablemente el fenómeno social más importante de los últimos diez años, por lo tanto, su influencia en el lenguaje ha permeado a la sociedad en todas sus esferas (Saldívar, 2014). En México el narcotráfico ha llegado a ser parte de la cotidianidad, un elemento que 
está presente en todo momento y que involucra a una gran cantidad de la población. Solamente en los últimos diez años se estima que ha habido más de 100,000 muertes de personas relacionadas con el narcotráfico y el fenómeno no parece disminuir en lo más mínimo.

Se habla del narcotráfico desde diversas perspectivas. El discurso oficial sobre los traficantes reproducido por los medios de comunicación contrasta enormemente con el generado por los compositores de narcocorridos. En el primero, no se distinguen las diferencias entra las categorías, solamente se les ve como el Anticristo (Astorga, 1997). A través del lenguaje, el narcotráfico se conceptualiza de formas diversas, por ejemplo, para los sinaloenses la muerte y la inseguridad no son tan "representativos" del narcotráfico como lo son el estatus que esta actividad genera a través de sus lujos, ornamentos, música y poder. En cambio, en Michoacán se objetiva por los daños que genera (Moreno Candil, Burgos Dávila, \& Valdez Bátiz, 2016).

Como se ha podido establecer en este trabajo, el narco lenguaje no es un ente homogéneo, se expresa de distintas formas según la perspectiva que se tenga de él. En el discurso oficial el narcotráfico es el enemigo a vencer, el cáncer social, mientras se busca enfatizar los esfuerzos de las autoridades por destruir esta amenaza. El discurso de la prensa se relaciona mucho con el discurso oficial, aunque se enmarca en una narrativa que destaca la lucha entre autoridades y traficantes, en especial los hechos de violencia y los grandes decomisos de drogas, de los cuales siempre se especifica el "valor estimado en la calle"; todo lo cual seguramente ayuda a lograr mayores ventas de periódicos.

En la literatura,se busca mostrar los rasgos humanos de aquellos que viven inmiscuidos de alguna forma en el fenómeno. Por un lado, los ensayos que estudian el fenómeno narco se acercan al lenguaje periodístico en los recursos narrativos, aunque además de resaltar la violencia, muestran la interacción, no siempre antagónica, entre autoridades y organizaciones criminales, y cómo, dentro de este marco, los individuos buscan hacer una vida.

En cuanto a las novelas acerca del narco, los traficantes incluso se presentan como los protagonistas, antihéroes que han optado por un estilo de vida que muchas veces tiene graves consecuencias. Curiosamente, este tipo de obras, al ser trasladadas al cine o la televisión, encuentran entre los narcotraficantes una audiencia interesada. De acuerdo a la Procuradora General de México, Arely López, la entrevista que dio Joaquín “El Chapo” 
Guzmán al actor Sean Penn y a la actriz Kate del Castillo (protagonista de la serie televisiva La reina del sur), fue determinante para la aprensión del capo (CNN, 2016); lo que indica que Guzmán Loera conocía la famosa serie y estaba interesado en que se llevara su vida a la pantalla.

De manera similar a la relación entre las narcoseries, los narcocorridos, por un lado, recogen las expresiones usadas por los narcotraficantes y, por otro, ayudan a modelar el imaginario del narcotráfico. Los narcocorridos que logran más aceptación se convierten en referencias que son posteriormente utilizadas por los propios narcotraficantes. Por otra parte, muestran individuos con un afán por lograr dinero, poder y placer, aún a sabiendas de que, literalmente, cada momento puede ser el último; todo esto con un tono festivo y despreocupado.

El lenguaje que se utiliza en los blogs demuestra también esta complejidad de la que hablamos. A pesar de que hay continuas referencias a la violencia y al terror que genera la operación de los carteles, también se manifiesta cierta dosis de humor, con expresiones que hacen mofa de los traficantes y de las autoridades por igual. Tal vez estas expresiones sean una forma de evasión de la realidad o, al contrario, un nivel de habituación a la violencia tal que es posible reírse hasta de las situaciones más crueles.

Finalmente, las narcomantas se han convertido en un tipo de diario oficial, señalan las posturas de los carteles respecto a diferentes asuntos a través de un lenguaje crudo y escueto que busca ser institucional. Pareciera que en ocasiones estos mensajes, además de amenazar a los contrarios, buscaran persuadir a la población de la legitimidad de las acciones de los carteles; lo cual hace pensar que para algunos de estos grupos es importante contar con el apoyo ciudadano.

Así pues, el lenguaje del narco es variado en sus formas, en sus temáticas y en sus intenciones, por lo tanto, si se busca entenderlo y, por ende, conocer un poco más del fenómeno narco en lo general, es necesario acercarse a su estudio desde la complejidad. Es imposible comprender el fenómeno desde un discurso maniqueo. Lo que antes era concebido como diametralmente opuesto, ahora es mantenido en oposición vinculante. Así, cada uno de los opuestos conserva su naturaleza, pero en un diálogo constructivo, posibilitando la emergencia de nuevas relaciones (Gallegos, 2016). Es necesario evitar la visión unidimensional y analizar la realidad como un tejido de eventos, acciones, interacciones, retroacciones, determinaciones, azares, que constituyen nuestro mundo (Morin, 1994). 


\section{Referencias bibliográficas}

Astorga, L. (1997). Los corridos de traficantes de drogas en México y Colombia. Revista mexicana de sociología, 245-261. . (2004). Mitología del narcotraficante en México. México D.F.: Plaza y Janés. . (2005). Corridos de traficantes y censura. Región y sociedad, XVII(3), 146-165.

Baker, P. (2010). Sociolinguistics and corpus linguistics. Edinburgh: Edinburgh University Press.

Biber, D. (2008). Representativeness in corpus design. En A. Fontenelle, Practical lexicography, a reader (pp. 63-87). Great Britain: Oxford University Press.

Burgos Dávila, C. J. (2013). Narcocorridos: Antecedentes de la tradición corridística y del narcotráfico en México. Studies in Latin American Popular Culture 31, 157-183.

CNN. (11 de 01 de 2016). CNNespanol. Recuperado el 26 de 08 de 2107, de http://cnnespanol.cnn.com/2016/01/11/la-entrevista-desean-penn-con-el-chapo-fue-esencial-para-su-captura-diceprocuradora-de-mexico/

Contreras Orozco, H. (7 de mayo de 2015). El lenguaje de los narcos. Al Margen. Recuperado el 26 de agosto de 2017, http://almargen. $\mathrm{mx} /$ el-lenguaje-de-los-narcos/

Diccionario del Español de México (DEM). El Colegio de México. Recuperado el 10 de abril de 2017, http://dem.colmex.mx.

Dueñas, G. P. (2013). Narrating narcos: Culiacan and Medellin. Pittsburgh: University of Pittsburgh Press.

Company, C. C. (2010). Diccionario de mexicanismos. México: Siglo XXI. Enciso, F. (2014). El origen del narco según la glosa popular sinaloense. Arenas. Revista sinaloense de ciencias sociales, (36), 10-33.

Fitch, R. (2011). Diccionario de coloquialismos y términos dialectales del español. Madrid: Arco Libros.

Gallegos, M. (2016). Una cartografía de las idea de la complejidad en América Latina: la difusión de Edgar Morin. Latinoamérica. Revista de estudios latinoamericanos, 3-128. 
Greimas, A. J. (1987). On meaning. Selected writings on semiotic theory (pp. 106-120). Minneapolis: U of Minnesota.

Hernández García, J. L. (5 de diciembre de 2016). El tamaño del fracaso: 186 mil muertos en una década de guerra en México, según datos oficiales. Sinembargo. Recuperado el 6 de diciembre de 2017, http://www.sinembargo.mx/05-12-2016/3121218

Himmelman, N. (2007). La documentación lingüística: ¿qué es y para qué sirve? En J. Haviland \& J. A. Flores Farfán, Bases de la documentación lingüística (pp. 15-47). México: Instituto Nacional de Lenguas Indígenas.

Kristiansen, G. (2008). Style-shifting and shifting styles: A socio-cognitive approach to lectal variation. En G. Kristiansen \& R. Dirven, Cognitive sociolinguistics. Language variation, cultural models, social systems (pp. 45-90). Berlin: Mouton de Gruyter.

Luján Christiansen, M. (2016). La insoportable levedad del discurso. Timos epistemológicos en la construcción mediática de la narcoviolencia. Mitologías hoy. Revista de pensamiento, crítica y estudios literarios latinoamericanos, 25-40.

Moreno Candil, D., Burgos Dávila, C. J., \& Valdez Bátiz, J. E. (2016). Daño social y cultural del narcotráfico en México: estudio de representaciones sociales en Sinaloa y Michoacán. Mitologías Hoy, 249-269.

Morin, E. (1994 ). Introducción al pensamiento complejo. Madrid: Gedisa. (1999). Los 7 saberes necesarios para la educación del futuro. Paris: UNESCO.

Ramírez Pimienta, J. (2010). Cantar a los narcos: Voces y versos del narcocorrido. México, DF.: Planeta.

Rodríguez Rejas, M. J. (2014). México: la cultura del miedo en un escenario de guerra. Estudios latinoamericanos. Nueva época, (34), 119-136.

Saldívar, R. (2014). Análisis lexicológico del narcolenguaje en Baja California. Mexicali: UABC. 